\title{
Feasibility and Effects of Newly Developed Balance Control Trainer for Mobility and Balance in Chronic Stroke Patients: A Randomized Controlled Trial
}

\author{
So Hyun Lee, M.D., Seung Deuk Byun, M.D. ', Chul Hyun Kim, M.D., Jin Young Go, M.D., \\ Hyeon Uk Nam, M.D., Jin Seok Huh, M.D., Tae Du Jung, M.D. \\ Department of Rehabilitation Medicine, Kyung-pook National University College of Medicine, Daegu 700-721, \\ ${ }^{1}$ Department of Rehabilitation Medicine, Dae-gu Fatima Hospital, Daegu 701-600, Korea
}

\begin{abstract}
Objective To investigate the feasibility and effects of balance training with a newly developed Balance Control Trainer (BCT) that applied the concept of vertical movement for the improvements of mobility and balance in chronic stroke patients.

Method Forty chronic stroke patients were randomly assigned to an experimental or a control group. The experimental group $(n=20)$ underwent training with a BCT for 20 minutes a day, 5 days a week for 4 weeks, in addition to concurrent conventional physical therapy. The control group $(n=20)$ underwent only conventional therapy for 4 weeks. All participants were assessed by: the Functional Ambulation Categories (FAC), 10-meter Walking Test (10mWT), Timed Up and Go test (TUG), Berg Balance Scale (BBS), Korean Modified Barthel Index (MBI), and Manual Muscle Test (MMT) before training, and at 2 and 4 weeks of training.

Results There were statistically significant improvements in all parameters except knee extensor power at 2 weeks of treatment, and in all parameters except MBI which showed further statistically significant progress in the experimental group over the next two weeks $(p<0.05)$. Statistically significant improvements on all measurements were observed in the experimental group after 4 weeks total. Comparing the two groups at 2 and 4 weeks of training respectively, 10mWT, TUG, and BBS showed statistically more significant improvements in the experimental group $(\mathrm{p}<0.05)$.

Conclusion Balance training with a newly developed BCT is feasible and may be an effective tool to improve balance and gait in ambulatory chronic stroke patients. Furthermore, it may provide additional benefits when used in conjunction with conventional therapies.
\end{abstract}

Key Words Balance, Gait, Mobility, Stroke

Received March 30, 2012; Accepted June 29, 2012

Corresponding author: Tae Du Jung

Department of Rehabilitation Medicine, Kyung-pook National University College of Medicine, 50, Samduck-dong 2ga, Jung-gu, Daegu 700-721, Korea

Tel: +82-53-420-5311, Fax: +82-53-423-0389,E-mail: teeed0522@ hanmail.net

(a) This is an open-access article distributed under the terms of the Creative Commons Attribution Non-Commercial License (http:// creativecommons.org/licenses/by-nc/3.0) which permits unrestricted noncommercial use, distribution, and reproduction in any medium, provided the original work is properly cited.

Copyright $\odot 2012$ by Korean Academy of Rehabilitation Medicine

\section{INTRODUCTION}

Stroke patients adopt an asymmetrical standing posture and experience difficulty when walking due to many factors, such as reduced muscular power, imbalance in weight distribution, impaired proprioception, exaggerated stretch reflex, spasticity, and impaired motor control. ${ }^{1}$ Although most stroke patients are known to retain some ability to walk, ${ }^{2,3}$ many patients still suffer from abnormal 
gait and limitations when walking any distance.

Because adequate postural control and balance are essential components of walking and mobility after a stroke, standing balance training, especially training that shifts the weight to the affected side, is fundamental. Therefore, many conventional treatments such as neurodevelopment treatment (NDT) and sensory stimulation make patients shift their weight to the affected side. ${ }^{4,5}$ Other functional walking training methods like weight unloading devices, robots, and balance training systems such as the Balance Master System and Balance Retrainer have been used to achieve this goal. ${ }^{6-14}$ However, these treatments have some limitations. They are used only in the horizontal plane, even though many activities of daily living (ADLs), for example the 'sit to stand' process are performed in the vertical plane. Making matters worse, these treatments are often perceived as tedious by patients. Therefore, our team developed a new balance trainer, a Balance Control Trainer (BCT). This system was developed to allow for exercises in both the horizontal and vertical planes. The system was composed of selfweight shifting exercises and video games that used visual feedback during task-specific lower limb exercises and video games that demonstrated weight shift not only the horizontal plane but also the vertical plane. Video games that use visual and auditory stimuli can improve patient satisfaction and enhance their compliance.

The aim of this study was to examine the feasibility and effects of a BCT that applied the concept of vertical movement to improve mobility and balance in chronic stroke patients.

\section{MATERIALS AND METHODS}

\section{Participants}

Forty subjects were recruited in Daegu, South Korea, between March 2010 and February 2011. The general characteristics are shown in Table 1. Patients were required to meet the following inclusion criteria in this study: (1) the patients at six months or greater after the stoke, (2) the first episode of unilateral stroke (infarction, hemorrhage) with hemiparesis, in the territory of the internal carotid artery, (3) the diagnosis of stroke confirmed by computed tomography or magnetic resonance imaging, (4) the ability to understand and follow simple verbal instructions, (5) was ambulatory before onset of stroke, (6) the ability to walk 10 meters independently.
They were excluded if they were medically unstable or had a history of musculoskeletal conditions affecting lower limbs or neurological diseases affecting vision, gait balance, conscious or cognitive level (Mini-Mental State Examination $[\mathrm{MMSE}]<24$ ). The protocol was approved by the Institutional Review Board (IRB) and informed consent was obtained prior to training.

\section{Design}

A prospective randomized controlled design was used. The 40 patients were randomized into an experimental group or a control group of 20 each. A randomization procedure was performed by an observer who was not involved in this intervention including the outcome measuring. The physician who conducted the gait analysis was blinded; however, patients and physiotherapists who used and applied a BCT were not blinded, because it was impossible of ethical and design reasons. As shown in Figure 1, no patients dropped out in this protocol (Fig. 1).

\section{Intervention}

Both groups participated in our conventional physical therapy for 1 hour a day, 5 days a week for 4 weeks. The

Table 1. Demographic and Baseline Characteristics

\begin{tabular}{llcc}
\hline Variable & & $\begin{array}{c}\text { Experimental } \\
\text { group (n=20) }\end{array}$ & $\begin{array}{c}\text { Control } \\
\text { group } \\
(\mathbf{n = 2 0})\end{array}$ \\
\hline Sex & Male & $13(65 \%)$ & $12(60 \%)$ \\
& Female & $7(35 \%)$ & $8(40 \%)$ \\
\hline Age (years) & & $53.75 \pm 11.29$ & $54.1 \pm 11.13$ \\
Time since onset (months) & $13.30 \pm 5.89$ & $14 \pm 6.34$ \\
\hline Type of injury & Infarction & $14(70 \%)$ & $13(65 \%)$ \\
\hline & Hemorrhage & $6(30 \%)$ & $7(35 \%)$ \\
\hline Affected side & Right & $8(40 \%)$ & $8(40 \%)$ \\
\hline & Left & $12(60 \%)$ & $12(60 \%)$ \\
\hline FAC & & $3.4 \pm 0.8$ & $3.3 \pm 1.0$ \\
\hline 10mWT (sec) & & $21.0 \pm 5.0$ & $22.4 \pm 14.5$ \\
\hline TUG (sec) & & $18.6 \pm 4.4$ & $20.1 \pm 4.3$ \\
\hline BBS & & $39.8 \pm 8.7$ & $40.0 \pm 6.8$ \\
\hline MBI & & $64.0 \pm 17.0$ & $65.6 \pm 13.5$ \\
\hline MMT & & $3.0 \pm 0.9$ & $3.2 \pm 0.6$ \\
\hline
\end{tabular}

Values are mean \pm S.D.

FAC: Functional ambulation categories, 10mWT: 10-meter walking test, TUG: Timed up and go test, BBS: Berg balance scale, MBI: Modified barthel index, MMT: Manual muscle test of the knee extensor 


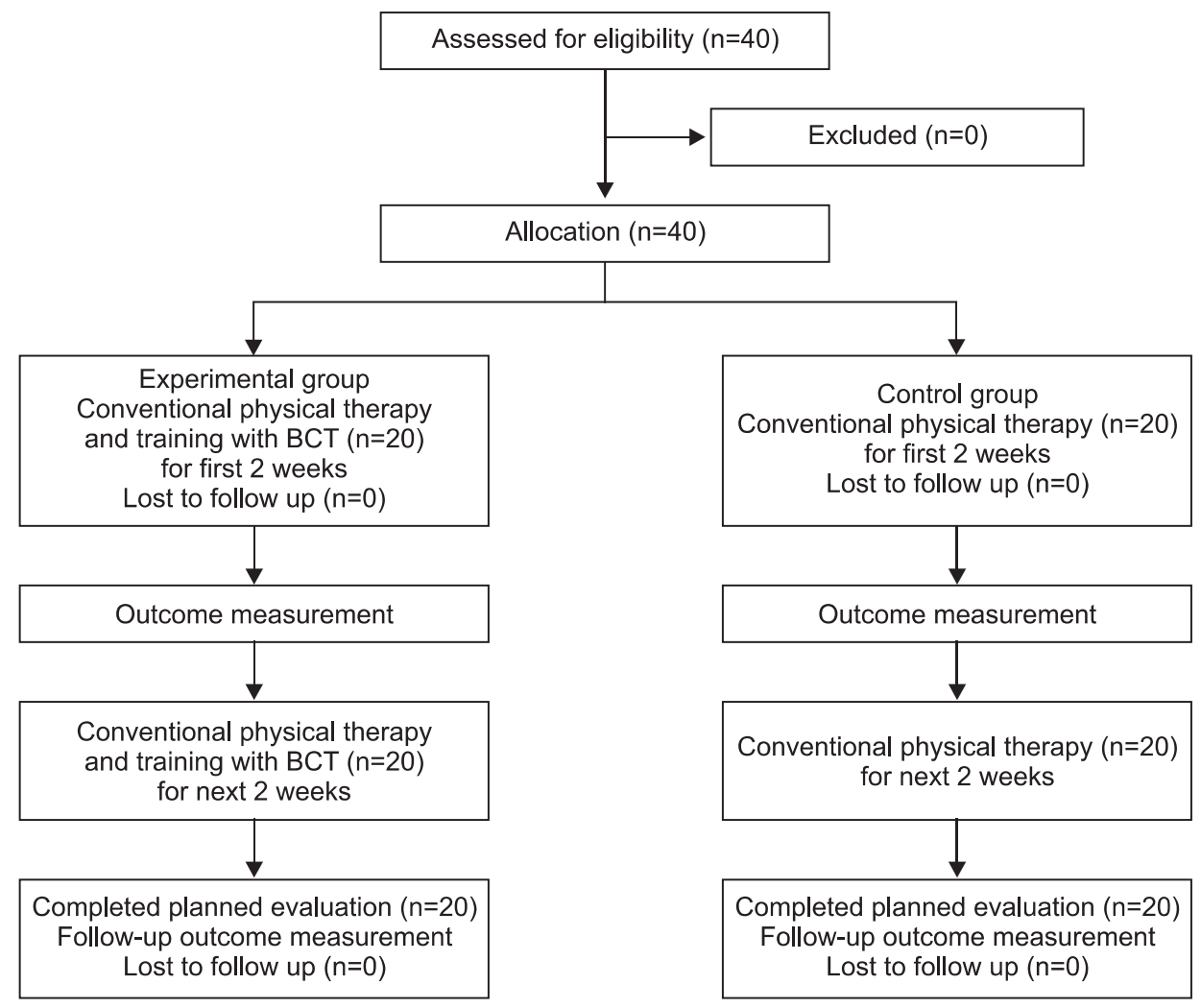

Fig. 1. Flow diagram of this study. BCT: Balance control trainer.

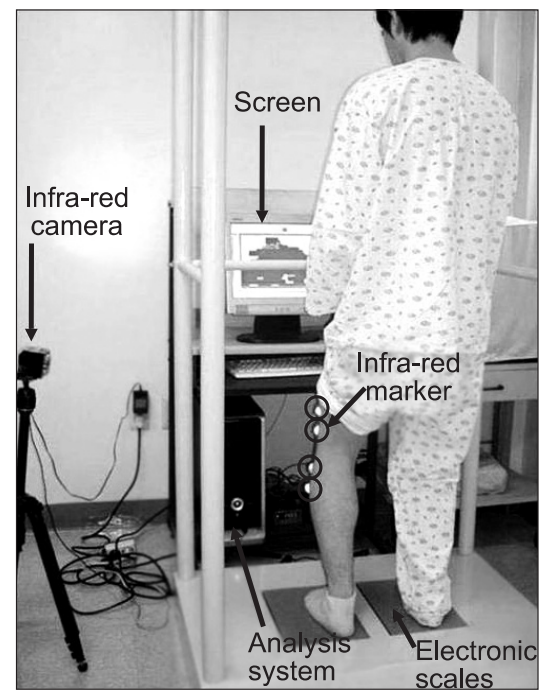

Fig. 2. A Balance Control Trainer consists of two electronic scales, an infrared camera, and a computerized system that allows training games to use the data collected.

experimental group received an additional 20 minutes of training using a BCT.

In this study, we used a newly developed BCT that had proven its effects on functional balance and gait through the preliminary research (Fig. 2). ${ }^{15}$ Training with a BCT

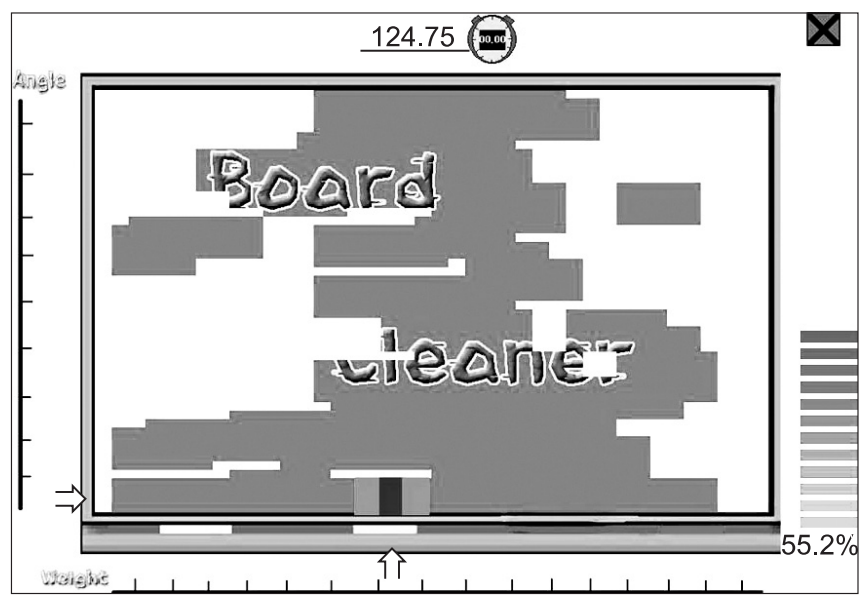

Fig. 3. The board cleaner game. When weight is shifted to either side, the cleaner moves horizontally and knee flexion/extension moves the cleaner vertically. The score is given as a percentage of the board cleaned in 2 minutes. The white area in this figure represents the area of the board that has been cleaned.

was composed of two different steps. First, a self-weight shifting exercise was performed in both the horizontal and vertical plane with visual feedback that was provided for 10 minutes. Patients were asked to stand on both feet and load as much weight as possible on the affected side 
without losing balance for the first 5 minutes. The distribution of weight on the left and right sides was monitored continuously during this time. During the next 5 minutes, patients were also asked to repetitively flex and extend the knee as far as they could on the affected side while still bearing weight as much weight as possible on that side.

Second, weight shifting exercises with the video game (board cleaner game) were performed for the next 10 minutes (Fig. 3). The game lasted for 2 minutes and was played 5 times. In the board cleaner game, an eraser would move left and right on the screen according to the horizontal weight shift to erase an image on the screen. The eraser would move vertically in response to knee flexion and extension. The objective of the activity was to erase as much of the board as possible in a given time. A 20-degree toe-out stance on the electronic scales and maximum plantar contact with the scales were maintained at all times in order to minimize rotation of the lower limb.

\section{Clinical tests}

All 40 patients underwent an objective assessment before training, and at 2 and 4 weeks of training. The Functional Ambulation Categories (FAC), 10-meter Walking Test (10mWT), Timed Up and Go test (TUG), the Berg Balance Scale (BBS), and the Modified Barthel Index (MBI) were used as clinical tools to measure the level of function, and the Manual Muscle Test (MMT) was used to measure the strength of knee extension. The reliability and validity of these clinical tests are well established. ${ }^{16-21}$

\section{Statistical analysis}

SPSS version 18.0 for Windows was used for statistical analysis. Demographic data were compared using the chi-square test and the independent sample t-test. The paired sample t-test was used to compare pre-treatment and post-treatment results within each group, and the independent sample t-test was used to compare the means between the study and control groups for each of the parameters assessed. Results were considered statistically significant if the p-value was less than 0.05 .

\section{RESULTS}

\section{General characteristics of patients}

Forty hemiplegic patients were enrolled in this study.
They were divided into two groups; the experimental group (13 males and 7 females, mean age of $53.75 \pm 11.29$ years, time since onset of $13.30 \pm 5.89$ months) and the control group (12 males and 8 females, mean age of $54.10 \pm 11.13$ years, time since onset of $14.00 \pm 6.34$ months) (Table 1).

There were no significant differences in: sex, age, time since the onset, the type of stoke, the side affected, FAC, $10 \mathrm{mWT}$ and TUG, BBS, MBI, and MMT of the knee extensor between the two groups ( $\mathrm{p}>0.05)$.

Feasibility of treatment with a newly developed Balance Control Trainer

No patient dropout occurred and all participants completed the assigned training program. No adverse effects were observed during the training period with the new balance trainer. Patients commented that they enjoyed training with the BCT because the game was entertaining.

\section{Training effects}

There were statistically significant improvements in all parameters (FAC, 10mWT, TUG, BBS, and MBI) except knee extensor power at 2 weeks of training in the experimental group, while only two parameters (BBS and MBI) in control group $(\mathrm{p}<0.05)$. And all parameters except MBI showed further statistically significant progress in the experimental group over the next two weeks, while only one parameter (10mWT) showed statistically significant progress in control group $(\mathrm{p}<0.05)$. Over the 4 week total, all parameters had statistically significant improvements in the experimental group, while only $10 \mathrm{mWT}$ was seen as improved in the control group (Fig. 4).

Comparing the two groups at 2 and 4 weeks of training respectively, parameters of $10 \mathrm{mWT}$, TUG, and BBS in the experimental group showed statistically more significant improvements at 2 weeks of treatment. And there were statistically significant differences between the two groups in FAC, 10mWT, TUG, and BBS at 4 weeks of treatment $(\mathrm{p}<0.05)$ (Table 2).

\section{DISCUSSION}

This is the first prospective, randomized controlled study to show that additional training with a newly developed Balance Control Trainer (BCT) could achieve greater improvements in mobility and balance in chronic 
(A)

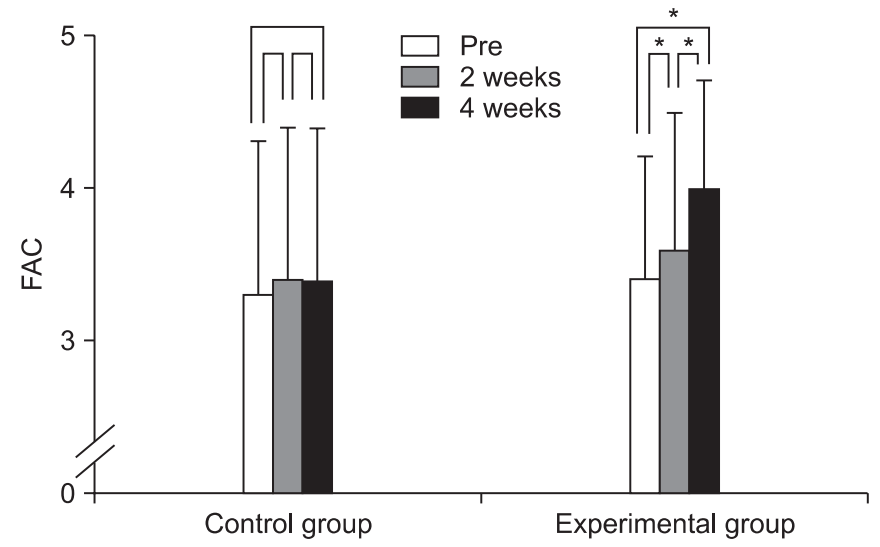

(C)

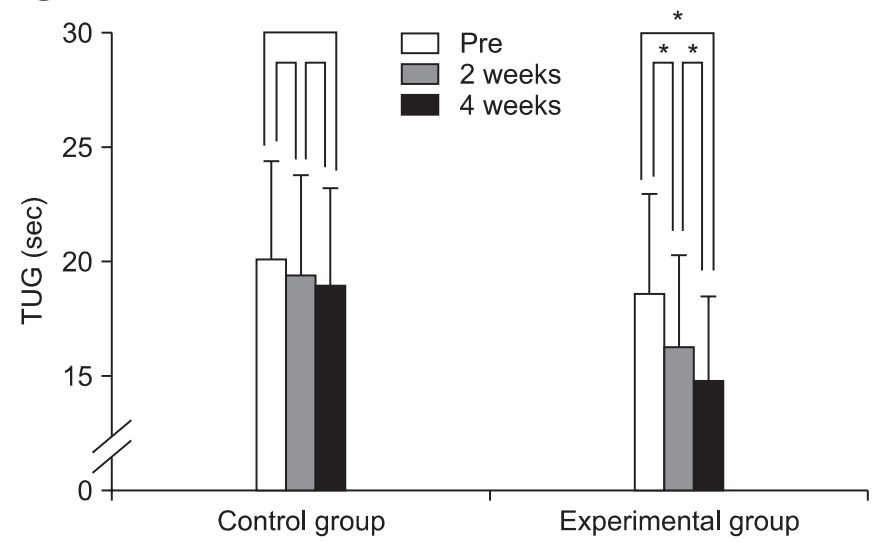

(E)

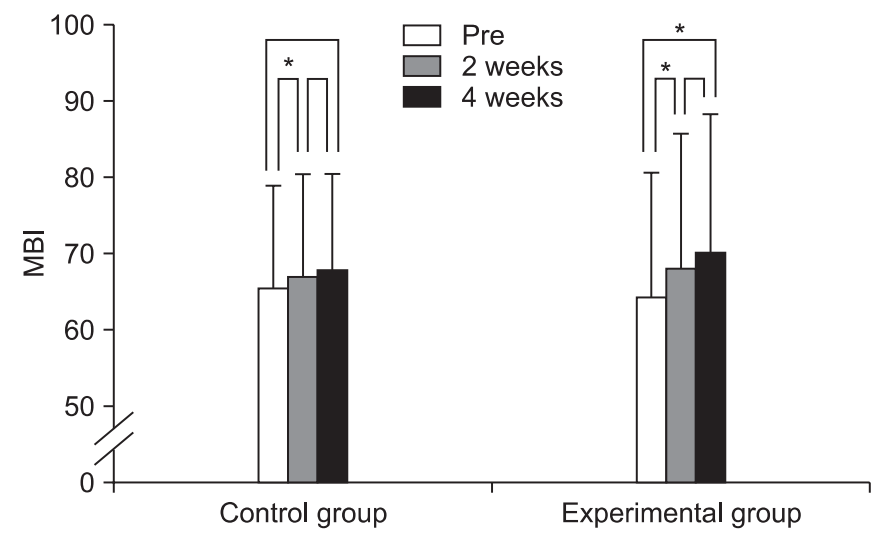

(B)

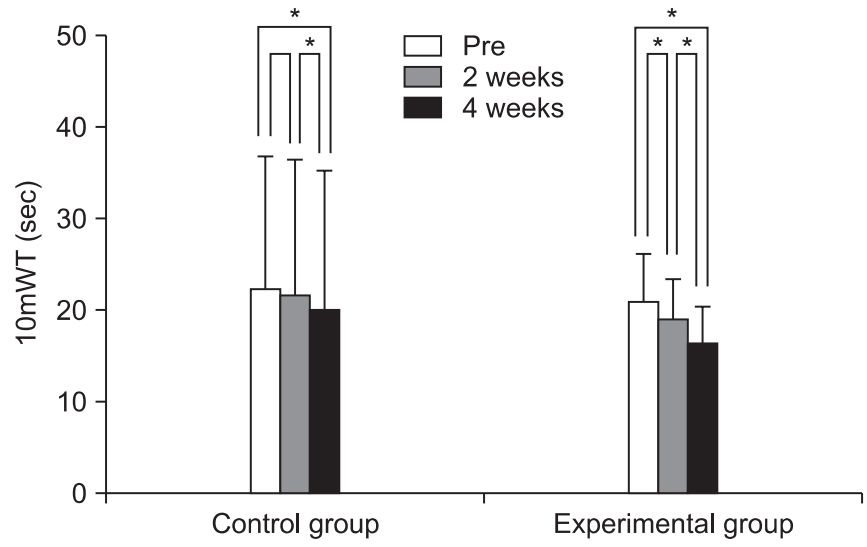

(D)

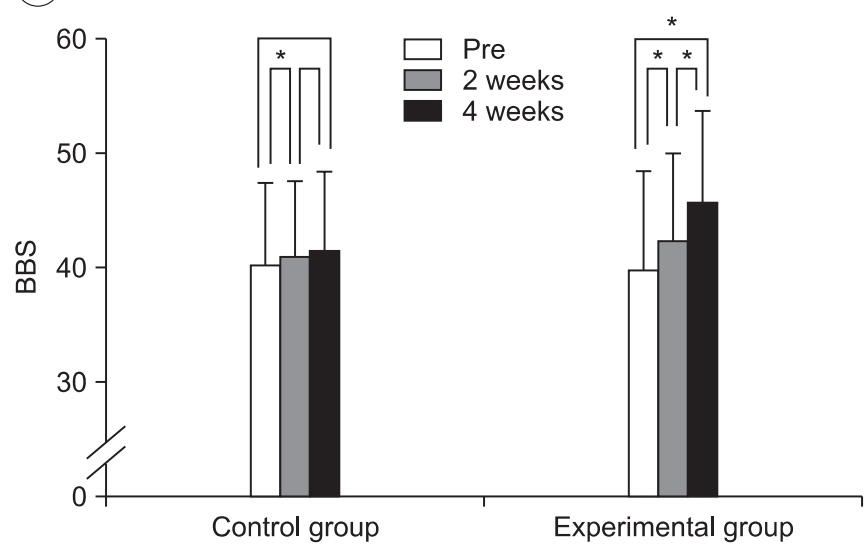

(F)

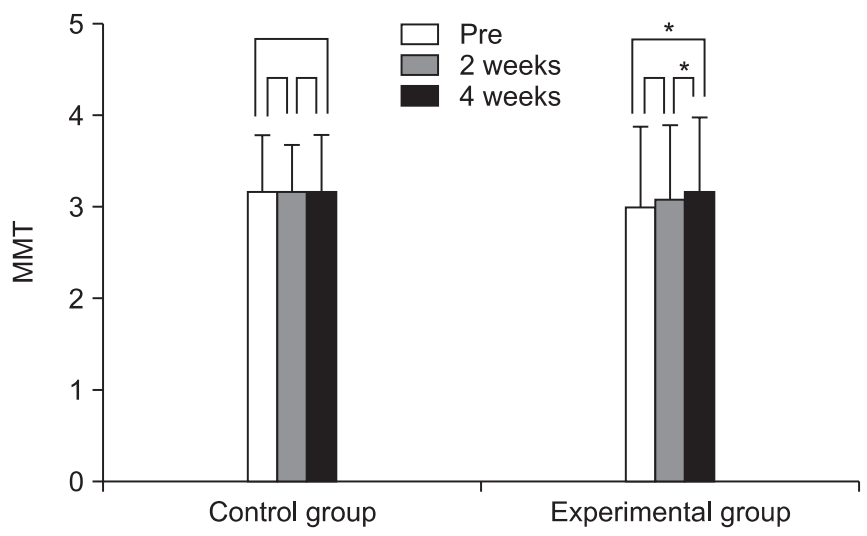

Fig. 4. 6 Parameters (FAC, 10mWT, TUG, BBS, MBI and MMT) were assessed before treatment, after 2 and 4 weeks of training. During the first 2 weeks, there were statistically significant improvements in all parameters (FAC, 10mWT, TUG, BBS and MBI) except for knee extensor power in the experimental group, while only two parameters (BBS and MBI) were in the control group. Over the next two weeks, all parameters except MBI showed further statistically significant progress in the experimental group, while only one parameter (10mWT) was seen in the control group. Over a total of 4 weeks, all parameters and statistically significant improvements in the experimental group, while it was only 10mWT in control group. FAC: Functional Ambulation Categories, 10mWT: 10-meter Walking Test, TUG: Timed Up and Go test, BBS: Berg Balance Scale, MBI: Modified Barthel Index, MMT: Manual Muscle Test of the knee extensor. ${ }^{*} \mathrm{p}<0.05$ by paired sample $\mathrm{t}$ test. 
Table 2. Quantitative Measurements of Parameters in the Experimental $(n=20)$ and Control Group ( $n=20)$

\begin{tabular}{|c|c|c|c|c|c|c|}
\hline \multirow{2}{*}{ Parameters } & \multicolumn{2}{|c|}{ Pre-treatment } & \multicolumn{2}{|c|}{ At 2 weeks } & \multicolumn{2}{|c|}{ At 4 weeks } \\
\hline & Experimental & Control & Experimental & Control & Experimental & Control \\
\hline FAC & $3.4 \pm 0.8$ & $3.3 \pm 1.0$ & $3.6 \pm 0.9$ & $3.4 \pm 1.0$ & $4.0 \pm 0.7^{\dagger}$ & $3.4 \pm 1.0$ \\
\hline $10 \mathrm{mWT}$ (sec) & $21.0 \pm 5.0$ & $22.4 \pm 14.5$ & $19.1 \pm 4.3^{*}$ & $21.7 \pm 15.0$ & $16.4 \pm 4.0^{\dagger}$ & $20.2 \pm 15.0$ \\
\hline TUG (sec) & $18.6 \pm 4.4$ & $20.1 \pm 4.3$ & $16.3 \pm 4.0^{*}$ & $19.5 \pm 4.3$ & $14.8 \pm 3.7^{\dagger}$ & $19.0 \pm 4.2$ \\
\hline BBS & $39.8 \pm 8.7$ & $40.0 \pm 6.8$ & $42.3 \pm 7.7^{*}$ & $41.1 \pm 6.7$ & $45.7 \pm 7.8^{\dagger}$ & $41.7 \pm 6.9$ \\
\hline MBI & $64.0 \pm 17.0$ & $65.6 \pm 13.5$ & $68.3 \pm 17.5$ & $67.3 \pm 13.3$ & $70.4 \pm 18.0$ & $68.1 \pm 12.6$ \\
\hline MMT & $3.0 \pm 0.9$ & $3.2 \pm 0.6$ & $3.1 \pm 0.8$ & $3.2 \pm 0.5$ & $3.2 \pm 0.8$ & $3.2 \pm 0.6$ \\
\hline
\end{tabular}

Values are mean \pm S.D.

FAC: Functional ambulation categories, 10mWT: 10-meter walking test, TUG: Timed up and go test, BBS: Berg balance scale, MBI: Modified barthel index, MMT: Manual muscle test of the knee extensor

${ }^{*} \mathrm{p}<0.05$ comparison between two groups at 2 weeks. ${ }^{\dagger} \mathrm{p}<0.05$ comparison between two groups at 4 weeks by the independent sample t-test

stroke patients.

The asymmetrical stance due to reduced weight bearing in the affected lower limb is one of the problems that frequently occurs in hemiplegic stroke patients, and it is known to adversely affect mobility and activities of daily living. ${ }^{22,23}$ Therefore, special attention has been given to therapies that help increase weight bearing on the affected side. ${ }^{24,25}$ As mentioned earlier, many conventional treatments such as neurodevelopmental training (NDT) and sensory stimulation have been performed to help patients shift their weight to the affected side. Nowadays, more functional walking training methods like weight unloading devices and robots and new balance training systems such as the Balance Master System and Balance Retrainer have been developed to make patients shift their weight to the affected side. ${ }^{4-14}$ The outcomes of these types of training are still under debate.

The treadmill, on which many recent studies have been conducted, is known as a more task-specific approach for improving gait in hemiplegic patients. Moseley et al. ${ }^{26}$ reported that the treadmill with body weight support improved walking dependence, velocity, and endurance more than the treadmill without body weight support.

Therapies that use robots have also been shown to be more effective than conventional physical treatments in achieving independent walking. This method was superior when assessing the distance walked in six minutes. ${ }^{27}$ Despite their potential therapeutic efficacy, these treatment methods require expensive equipment and have yet to demonstrate sufficient cost-effectiveness.

Yavuzer et al. ${ }^{28}$ reported that an additional 15 minutes of balance training with the Force Plate Visual Feedback produced superior results in pelvic excursion as compared to neurodevelopmental training (NDT) alone, not including walking velocity. However, Eser et al., ${ }^{29}$ who used an identical method in their study, but used more functional testing tools such as the Brunnstrom stage, Rivermead Mobility Index (RMI), and Functional Independence Measurement (FIM), reported that there was no statistically significant difference between the outcomes of the two treatment regimes. Winstein et al. ${ }^{25}$ reported that 3-4 weeks of visual feedback treatment significantly improves symmetry, but not for walking. There is insufficient evidence to suggest that Force Plate Visual Feedback treatment leads to a significant improvement in the performance of functional activities such as walking. ${ }^{30,31}$ This treatment is used only in the horizontal plane, even though many activities of daily living are performed in the vertical plane even in normal people.

Our team developed the BCT in order to incorporate the vertical component of the center of gravity movement by means of knee joint involvement and the horizontal component into therapy, thus overcoming the main limitations associated with the Balance Master System.

We found that the ability to control the affected knee and the scores of the "board cleaner" game correlated with all clinical parameters including FAC, BBS, 10mWT, TUG, MBI and MMT of the knee extensor in a preliminary study. ${ }^{15}$ We used this device to rehabilitate hemiplegic stroke patients and to compare their improvements in balance and ability to walk to those of patients who received only conventional rehabilitation treatments.

In this study, there were statistically significant improvements in clinical parameters such as FAC, 10mWT, 
TUG, and BBS over 4 weeks of treatment. But there was no significant difference during the first 2 weeks in MMT of the knee extensor and last 2 weeks in MBI. However after 4 weeks there were definite improvements in MBI and MMT. It was explained in two ways. First, MBI consists of many items relating to patients' functional performance as well as the item evaluating gait ability. Therefore the interventions that improve gait ability might have no influence on the activities of daily living in last 2 weeks. The definite improvement in the MMT of the knee extensor was shown over the last 2 weeks. Its visible effect needs an even longer intervention period than other parameters.

Although this study also showed that conventional treatments were helpful in improving clinical parameters, we found that additional training with a newly developed BCT could be a better treatment option for mobility and balance in chronic stroke patients.

Barclay-Goddard et al. ${ }^{30}$ showed that the Balance Master System failed to improve BBS or TUG while moving or walking. These results may have been due to the fact that vertical movements of the center of gravity, which are essential components of independent walking and other activities of daily living such as standing up from a chair and sitting down again, were not taken into consideration in the treatment design. ${ }^{32-34}$ They suggested that the learning methods used in previously mentioned studies were not appropriately task-specific for walking or other activities of daily living. ${ }^{30,31}$ This means that a BCT may be a more effective rehabilitation treatment than conventional treatments in improving mobility and balance because a BCT takes into consideration the importance of movements in the vertical plane.

This study has some limitations. It was not a blind study as previously mentioned. It was impossible to hide the intervention intended for each patient from both the patient and the physiotherapist who were directly involved. Also the control group did not receive placebo therapy. This may have influenced the results but we did not consider it ethical to provide the patients with no treatment for 20 minutes.

In addition, the attention of physiotherapist on the experimental group may have caused a bias, even though it was only for 20 minutes of extra management. Long-term treatment of more than 4 weeks is needed to evaluate and confirm the effect on MMT. Also assessing the longterm effects of the treatment is also necessary; thus there should be ongoing follow-up beyond the completion of the treatment. Because we recruited only patients with a certain level of independent walking ability, these findings may not be applied to patients in the chronic stage of their illness, who have greater mobility problems. Such a study is currently in progress, working on the assumption that the experiment could be useful for severely impaired individuals, including those who are unable to walk, if a weight unloading system is used.

Despite these limitations, this study showed that training chronic stroke patients with a newly developed balance trainer is a feasible and potentially effective intervention to improve balance and mobility.

\section{CONCLUSION}

The training of chronic ambulatory stroke patients with BCT by administering a more task-specific and functional treatment especially focusing on mobility and balance, was feasible. And a BCT used in conjunction with conventional rehabilitation therapies can be more effective than conventional therapies alone.

\section{REFERENCES}

1. Brandstater ME, de Bruin H, Gowland C, Clark BM. Hemiplegic gait: analysis of temporal variables. Arch Phys Med Rehabil 1983; 64: 583-587

2. Skilbeck CE, Wade DT, Hewer RL, Wood VA. Recovery after stroke. J Neurol Neurosurg Psychiatry 1983; 46: 5-8

3. Wade DT, Wood VA, Hewer RL. Recovery after stroke-the first 3 months. J Neurol Neurosurg Psychiatry 1985; 48: 7-13

4. Bobath B. Adult hemiplegia: evaluation and treatment, 3rd ed, London: Butterworth-Heinemann, 1990, 70-160

5. Lorish TR, Sandin KJ, Roth EJ, Noll SF. Stroke rehabilitation. 3. Rehabilitation evaluation and management. Arch Phys Med Rehabil 1994; 75: S47-51

6. Hesse S, Bertelt C, Jahnke MT, Schaffrin A, Baake P, Malezic M, Mauritz KH. Treadmill training with partial body weight support compared with physiotherapy in nonambulatory hemiparetic patients. Stroke 1995; 26: 976-981

7. Hesse S, Bertelt C, Schaffrin A, Malezic M, Mauritz $\mathrm{KH}$. Restoration of gait in nonambulatory hemiparetic 
patients by treadmill training with partial body-weight support. Arch Phys Med Rehabil 1994; 75: 1087-1093

8. Patton J, Brown DA, Peshkin M, Santos-Munne JJ, Makhlin A, Lewis E, Colgate EJ, Schwandt D. KineAssist: design and development of a robotic overground gait and balance therapy device. Top Stroke Rehabil 2008; 15: 131-139

9. Mayr A, Kofler M, Quirbach E, Matzak H, Frohlich K, Saltuari L. Prospective, blinded, randomized crossover study of gait rehabilitation in stroke patients using the Lokomat gait orthosis. Neurorehabil Neural Repair 2007; 21: 307-314

10. Husemann B, Muller F, Krewer C, Heller S, Koenig E. Effects of locomotion training with assistance of a robot-driven gait orthosis in hemiparetic patients after stroke: a randomized controlled pilot study. Stroke 2007; 38: 349-354

11. Chen IC, Cheng PT, Chen CL, Chen SC, Chung CY, Yeh TH. Effects of balance training on hemiplegic stroke patients. Chang Gung Med J 2002; 25: 583-590

12. Nichols DS. Balance retraining after stroke using force platform biofeedback. Phys Ther 1997; 77: 553-558

13. Liston RA, Brouwer BJ. Reliability and validity of measures obtained from stroke patients using the Balance Master. Arch Phys Med Rehabil 1996; 77: 425-430

14. Matjacic Z, Hesse S, Sinkjaer T. BalanceReTrainer: a new standing-balance training apparatus and methods applied to a chronic hemiparetic subject with a neglect syndrome. NeuroRehabilitation 2003; 18: 251259

15. Kim CH, Byun SD, Shin OS, Kim TG, Kwon SM, Noh JH, Lee YS, Jung SK. Effects of the balance control of the affected lower extremity on balance and gait in hemiparetic patients. J Korean Acad Rehab Med 2008; 32: 394-399

16. Yelnik A, Bonan I. Clinical tools for assessing balance disorders. Neurophysiol Clin 2008; 38: 439-445

17. Jung HY, Park JH, Shim JJ, Kim MJ, Hwang MR, Kim SH. Reliability test of Korean version of Berg balance scale. J Korean Acad Rehab Med 2006; 30: 611-618

18. Mehrholz J, Wagner K, Rutte K, Meißner D, Pohl M. Predictive validity and responsiveness of the functional ambulation category in hemiparetic patients after stroke. Arch Phys Med Rehabil 2007; 88: 1314-1319

19. Pohl PS, Duncan PW, Perera S, Liu W, Lai SM, Studenski S, Long J. Influence of stroke-related impairments on performance in 6-minute walk test. J Rehabil Res Dev 2002; 39: 439-444

20. Podsiadlo D, Richardson S. The timed "Up \& Go": a test of basic functional mobility for frail elderly persons. J Am Geriatr Soc 1991; 39: 142-148

21. Jung HY, Park BK, Shin HS, Kang YK, Pyun SB, Paik NJ, Kim SH, Kim TH, Han TR. Development of the Korean version of modified Barthel index (K-MBI): Multicenter study for subjects with stroke. J Korean Acad Rehab Med 2007; 31: 283-297

22. Winstein CJ. Knowledge of results and motor learning-implications for physical therapy. Phys Ther 1991; 71: 140-149

23. Dickstein R, Nissan M, Pillar T, Scheer D. Foot-ground pressure pattern of standing hemiplegic patients. Major characteristics and patterns of improvement. Phys Ther 1984; 64: 19-23

24. de Haart M, Geurts AC, Dault MC, Nienhuis B, Duysens J. Restoration of weight-shifting capacity in patients with postacute stroke: a rehabilitation cohort study. Arch Phys Med Rehabil 2005; 86: 755-762

25. Winstein CJ, Gardner ER, McNeal DR, Barto PS, Nicholson DE. Standing balance training: effect on balance and locomotion in hemiparetic adults. Arch Phys Med Rehabil 1989; 70: 755-762

26. Moseley AM, Stark A, Cameron ID, Pollock A. Treadmill training and body weight support for walking after stroke. Cochrane Database Syst Rev 2005: CD002840

27. Mehrholz J, Werner C, Kugler J, Pohl M. Electromechanical-assisted training for walking after stroke. Cochrane Database Syst Rev 2007: CD006185

28. Yavuzer G, Eser F, Karakus D, Karaoglan B, Stam HJ. The effects of balance training on gait late after stroke: a randomized controlled trial. Clin Rehabil 2006; 20: 960-969

29. Eser F, Yavuzer G, Karakus D, Karaoglan B. The effect of balance training on motor recovery and ambulation after stroke: a randomized controlled trial. Eur J Phys Rehabil Med 2008; 44: 19-25

30. Barclay-Goddard R, Stevenson T, Poluha W, Moffatt ME, Taback SP. Force platform feedback for standing balance training after stroke. Cochrane Database Syst Rev 2004: CD004129

31. Richards CL, Malouin F, Wood-Dauphinee S, Williams JI, Bouchard JP, Brunet D. Task-specific physical ther- 
apy for optimization of gait recovery in acute stroke patients. Arch Phys Med Rehabil 1993; 74: 612-620

32. Lee MY, Wong MK, Tang FT, Cheng PT, Lin PS. Comparison of balance responses and motor patterns during sit-to-stand task with functional mobility in stroke patients. Am J Phys Med Rehabil 1997; 76: 401-410

33. Cheng PT, Liaw MY, Wong MK, Tang FT, Lee MY, Lin
PS. The sit-to-stand movement in stroke patients and its correlation with falling. Arch Phys Med Rehabil 1998; 79: 1043-1046

34. Vander Linden DW, Brunt D, McCulloch MU. Variant and invariant characteristics of the sit-to-stand task in healthy elderly adults. Arch Phys Med Rehabil 1994; 75: 653-660 